OPEN ACCESS

Edited by:

Peter John Shortland,

Western Sydney University, Australia

Reviewed by:

Karim A. Sarhane,

University of Toledo, United States

David Mahns,

Western Sydney University, Australia

*Correspondence:

Wei Yang

wei88linda@yahoo.com

Specialty section:

This article was submitted

to Neurotrauma,

a section of the journal

Frontiers in Neurology

Received: 16 February 2017

Accepted: 08 May 2017

Published: 08 June 2017

Citation:

Fu X, Wu H, Li J, Wang C, Li M, Ma $Q$ and Yang W (2017) Efficacy of

Drug Interventions

for Chemotherapy-Induced

Chronic Peripheral Neurotoxicity:

A Network Meta-analysis.

Front. Neurol. 8:223.

doi: 10.3389/fneur.2017.00223

\section{Efficacy of Drug Interventions for Chemotherapy-Induced Chronic Peripheral Neurotoxicity: A Network Meta-analysis}

\author{
Xiying $\mathrm{Fu}^{1}$, Huijie $\mathrm{Wu}^{2}$, Jinyao $\mathrm{Li}^{2}$, Can Wang ${ }^{2}$, Ming $\mathrm{Li}^{2}$, Qianqian $\mathrm{Ma}^{2}$ and Wei Yang ${ }^{2 *}$ \\ ${ }^{1}$ Department of Endocrinology, The Second Hospital of Jilin University, Changchun, Jilin, China, ${ }^{2}$ Department of Neurology, \\ The Second Hospital of Jilin University, Changchun, Jilin, China
}

Peripheral neurotoxicity is a disturbing issue for cancer patients who are treated with chemotherapy. Several medications have been developed for preventing chemotherapy-induced chronic neurotoxicity (CICNT) however; their relative efficacies have not yet been studied. In this study, we conducted a network meta-analysis to give intervention recommendations. The literature was searched in a variety of databases and eligible studies were chosen based on predefined criteria. Data extraction and statistical analysis was performed, and the results are displayed using the odds ratio (OR) and corresponding 95\% credible intervals (Crl) with respect to overall and severe neurotoxicity. The medications were ranked according to their surface under cumulative ranking curve values. The consistency of direct and indirect evidence was also evaluated. We found that patients with amifostine or vitamin $E(V E)$ treatment exhibited a lower risk of overall neurotoxicity compared to those using the placebo (amifostine: OR $=0.10,95 \%$ Crl: 0.02-0.46; VE: OR $=0.08,95 \% \mathrm{Crl}: 0.01-0.99)$. In regard to preventing severe neurotoxicity, glutathione and amifostine treatment appeared to be significantly more effective than the placebo (glutathione: $\mathrm{OR}=0.19,95 \% \mathrm{Crl}$ : 0.04-0.64; amifostine: $\mathrm{OR}=0.12,95 \% \mathrm{Crl}:$ 0.02-0.48). In summary, amifostine, VE, and glutathione treatment is considered to be effective in lowering the risk of CICNT. However, further studies which consider safety are required.

Keywords: chemotherapy-induced chronic neurotoxicity, network meta-analysis, efficacy, treatment, intervention

\section{INTRODUCTION}

Chemotherapy is widely used as a cancer treatment; however, it induces peripheral neurotoxicity in patients (1). There are two main types of neuropathy that may be induced by different kinds of chemotherapies, acute neuropathy, and chronic neuropathy (2). Acute neuropathy normally only lasts 1 week, and it is not dose related to chemotherapeutics. Chronic neuropathy is dose-related and can lead to a more debilitating influence on patients by causing paresthesia or proprioceptive changes (3). As acute neuropathy is reversible and does not cause severe harm to the peripheral nervous system $(2,4-6)$, more attention is given to chronic peripheral neurotoxicity. In this study, we also focus on chronic neurotoxicity. 
Various drugs are recommended to help prevent chemotherapy-induced chronic neurotoxicity (CICNT). Calcium and magnesium infusion, glutathione, amifostine, and vitamin $\mathrm{E}$ (VE) are the most favored treatments in terms of their effectiveness in weakening the neuropathy caused by cisplatin and other chemotherapeutics (7). The most widely used therapy for the prevention and treatment of CICNT is calcium and magnesium infusion. It is suggested to be implemented by approximately $50 \%$ of oncologists in their practices (8). However, the question of whether the use of calcium and magnesium infusion can actually reduce neurotoxicity remains controversial. Some studies $(9,10)$ proved its value in neuroprotection function while others $(2,8,11)$ denied its effectiveness. Glutathione is also known as a promising and effective drug. Preliminary clinical trials which assessed the efficacy of glutathione demonstrated a decline in neurotoxicity and no negative interference in oncolytic activity $(12,13)$. Another organic thiophosphate drug called amifostine also displayed the capability to defend against the cytotoxic effects on tissues posed by chemotherapy and radiotherapy (14). It has also been proven to be neuroprotective when used in combination with various chemotherapies such as cisplatin (14), cyclophosphamide (14), oxaliplatin (15), and carboplatin (16). VE is an antioxidant that can eliminate free radicals in cells. Based on current studies, it is also believed to be able to protect against cisplatin-induced neuropathy $(7,17)$. A decreased VE level in plasma was detected in patients suffering from cisplatin-induced neuropathy (17). A recent study proposed that the supplementation of VE can significantly reduce peripheral nerve damage induced by cisplatin (neurotoxicity incidence rate of $21.4 \%, 68.5 \%$ in the controls) (18).

Despite the fact that the effectiveness of the above therapies has been confirmed by many trials, the lack of head-to-head comparisons is a main drawback of current literature. There is also paradoxical evidence regarding the efficacy and safety of these chemicals when applied to CICNT. This may partly result from different patient backgrounds, type of chemotherapy, or neurotoxicity scales. This inconsistency further adds to the complexity in correctly deducing a conclusion on their real effectiveness. Furthermore, the published meta-analyses mainly focus on the clinical comparisons between calcium and magnesium infusion, glutathione, and amifostine (7, 19-23). Therefore, they do not provide sufficient evidence on the relative efficacy of each drug. No intervention for CICNT has been generally accepted or identified based on MA outcomes $(7,24)$.

A network meta-analysis (NMA) also known as a multipletreatment comparison allows for the synchronous extraction and analysis of data from medical trials. Unlike the conventional MA, it compares at least three interventions simultaneously and provides strong evidence on the relative efficacy of each treatment based on direct and indirect evidence $(25,26)$. This method has recently been utilized in many studies that aim to assess and compare the effectiveness of various therapeutic interventions (27-30). It also provides a useful and comprehensive summary that contributes to determining treatment.

By implementing an NMA in this study, our primary objective was to identify the most effective intervention to decrease the neurotoxicity caused by chemotherapy. We divided the related chronic neurotoxicity endpoints into two categories: the incidence of overall CICNT and the incidence of severe CICNT in patients. It should be noted that no NMA has been performed on the interventions of CICNT to date. Therefore, this study is quite necessary and may be very meaningful.

\section{MATERIALS AND METHODS}

\section{Literature Search}

Published literature was first retrieved from the medical databases [Medline, Embase, and China National Knowledge Internet (CNKI)] regardless of language. The search terms were "neurotoxicity syndromes," "calcium and magnesium," "glutathione," "vitamins," "amifostine," and "randomized controlled trial" and their synonyms. We removed duplicates, manually scanned the titles and abstracts, and reviewed the contents of studies to be involved. In order to prevent any omission, the reference lists were also examined. All the screening work was independently completed by two experienced researchers. If any disagreement arose, a discussion including a third party was performed to offer a mediated plan.

\section{Selection Criteria}

There were four inclusion criteria: (1) the study contains the assessment of chemotherapy-induced neurotoxicity in cancer patients; (2) the study contains at least one pairwise comparison between the drugs (placebo, calcium and magnesium, glutathione, amifostine, and VE); (3) the study provides enough data, for example, the number of patients under each grade of neurotoxicity; (4) and the study assesses the incidence of chemotherapy-induced overall chronic peripheral neurotoxicity (referred to as overall neurotoxicity below) or the incidence of chemotherapy-induced severe chronic peripheral neurotoxicity (referred to as severe neurotoxicity below) as endpoints.

\section{Data Extraction}

Two independent investigators were arranged to collect relevant data from each eligible study. Information consisting of name of author, publication year, type of randomization, type of blinding method, neurotoxicity assessment standard, tumor site, type of chemotherapy, type of intervention, sample size, dose as well as the overall neurotoxicity and severe neurotoxicity response was recorded. We implemented an NMA to identify the relative efficacy of different interventions (calcium and magnesium, glutathione, amifostine, VE, and placebo) of chemotherapy-induced chronic peripheral neurotoxicity. The endpoints of this study were overall neurotoxicity and severe neurotoxicity. The grade of neurotoxicity was classified according to several neurotoxicity assessment criteria such as the National Cancer Institution Common Toxicity Criteria (NCI-CTC) (31), World Health Organization (WHO) Criteria (32), and Oxaliplatin Special Scale (OSS) (33). Severe neurotoxicity was defined as a higher than grade 2 assessment of damage posed on the nervous system.

\section{Statistical Analysis}

A series of standard statistical analyses were implemented during the NMA. First, if possible we conducted a direct pairwise comparison between different treatments, and used the odds 
ratios (ORs) of incidence and the associated 95\% confidence intervals (CIs) to display the results. A lower OR indicates a better efficacy. Next, network plots were graphed to describe the scale of published studies, and the number of studies, which included a direct comparison between two specific interventions, was also labeled. After the indirect evidence between two interventions was derived from their respective comparisons with the same third party, direct and indirect evidence was combined in the network comparisons. These data were quantitatively described using the ORs of incidence and the associated 95\% credible intervals (CrI). A $P$-value of less than 0.05 denotes a statistically significant difference. Furthermore, the surface under cumulative ranking curve (SUCRA) of each treatment was utilized to identify and rank the most effective drugs for both overall and severe neurotoxicity. Typically, a higher SUCRA value indicates a greater satisfaction of treatment for a certain endpoint. A cluster analysis was also performed to come up with a final recommendation. In addition, the consistency between direct and indirect evidence was assessed using node splitting plots (which compared the ORs calculated from an MA and an NMA) and heat plots (where greater color intensity suggests a higher degree of inconsistency). We also calculated the Cochran's Q-statistics and conducted an inconsistency $I^{2}$ test to evaluate heterogeneity. A $P$-value of less than 0.1 in the Cochran's $Q$-test or greater than $50 \%$ value in the $I^{2}$ value illustrated significant heterogeneity. If any significant heterogeneous evidence was noted, the randomeffects model was implemented instead of the commonly used fixed-effects model. Publication bias was assessed using funnel plots. The NMA was based on Bayesian framework, and data were analyzed using the WinBUGS, R 3.2.3 (with some specific packages such as "meta," "gemtc," "igraph," and "netmeta"), and STATA 13.0 software.

\section{RESULTS}

\section{Study Characteristics}

A total of 1,839 potentially relevant publications were retrieved from the Medline, Embase, and CNKI databases. A total of 348 duplicates were removed, and the remaining 1,491 records were further screened according to their titles, abstracts, and contents. Finally, 23 articles were selected to be included in the study and their publication dates ranged from 1995 to 2014 (2, 8-18, 34-44). A flowchart of identification, screening, and inclusion is shown in Figure S1 in Supplementary Material. The Jadad scale of the 23 included studies is listed in the Table S1 in Supplementary Material. This NMA involved five different treatments, including a placebo, calcium and magnesium infusion, glutathione, amifostine, and VE. The efficacy outcomes we studied were based on the ability of the above drugs to decrease overall and severe neurotoxicity in chemotherapy-treated cancer patients. The network plot in Figure 1 shows the current research situation of these treatments. After adding up the sample sizes of the same treatment group in different involved studies, the total sample size of glutathione was the largest and VE was the smallest (with only 29). Furthermore, glutathione was most frequently compared (compared with a placebo in seven studies, with $\mathrm{Ca} / \mathrm{Mg}$ in one study, and with amifostine in one study). Table 1 provides basic information on the included studies.

\section{Overall Neurotoxicity}

According to the direct comparison results between different neurotoxicity treatments (Table 2), subjects treated with glutathione, VE, and amifostine showed a reduced risk of overall neurotoxicity compared with those treated with the placebo (glutathione: $\mathrm{OR}=0.64,95 \% \mathrm{CI}$ : $0.47-0.86$; VE: $\mathrm{OR}=0.34,95 \%$
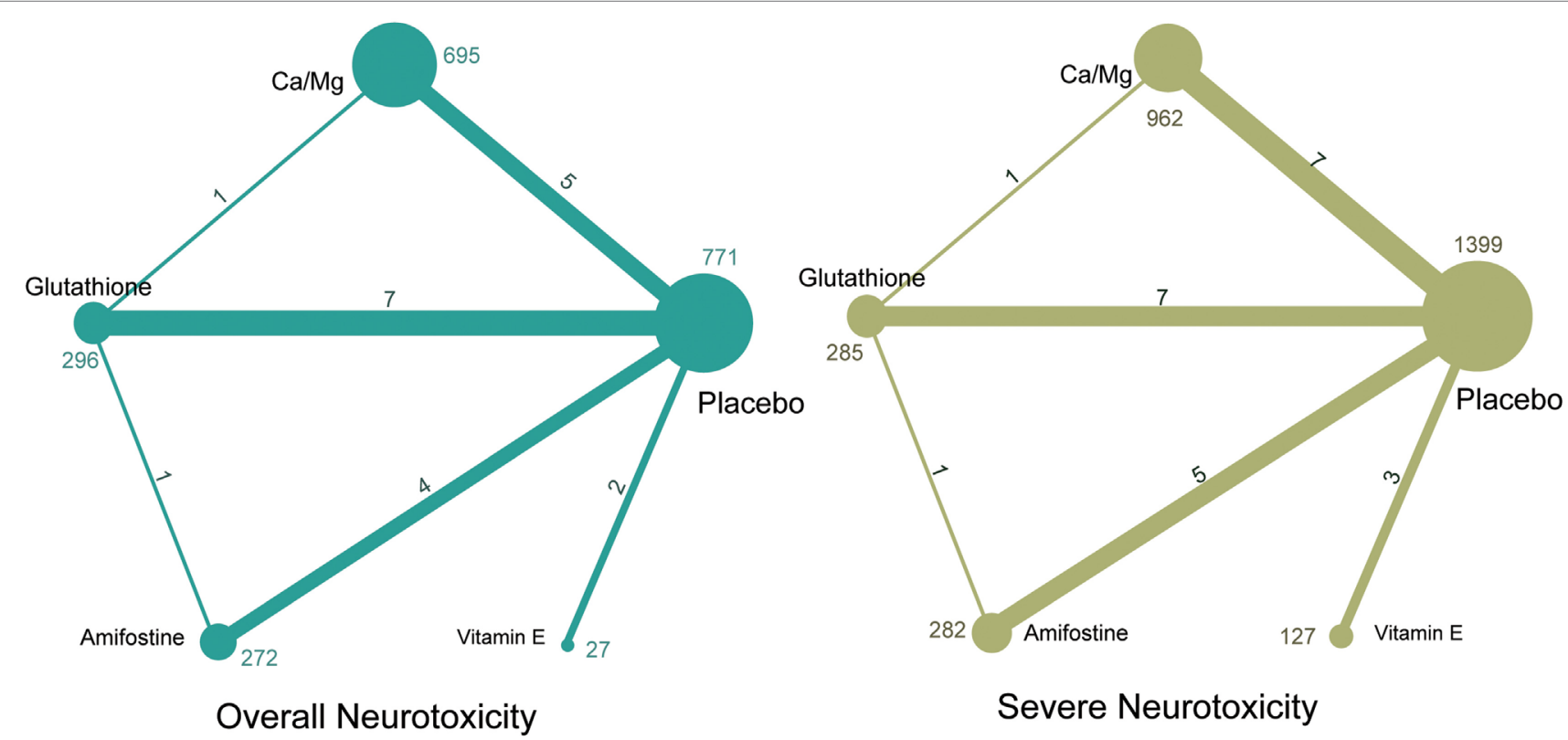

Severe Neurotoxicity

FIGURE 1 | Network of randomized controlled trials comparing different interventions of neurotoxicity. Numbers above lines represent direct comparisons between two interventions. Numbers above dots shows the total size of interventions. 
TABLE 1 | Main characteristics of included studies.

Study Randomization Blind Standard

Patients

Group 1

Group 2

Dose

Overall neurotoxicity

Severe neurotoxicity

\begin{tabular}{|c|c|c|c|c|c|c|c|c|c|c|c|c|c|c|}
\hline & & & & Tumor site & Chemotherapy & Treatment & Size & Treatment & Size & & Group 1 & Group 2 & Group 1 & Group 2 \\
\hline Grothey et al. (11) & Yes & $\begin{array}{l}\text { Double- } \\
\text { blind }\end{array}$ & $\mathrm{NCl}-\mathrm{CTC}$ & Colorectal & Oxaliplatin & $\mathrm{Ca} / \mathrm{Mg}$ & 50 & Placebo & 52 & Ca: $1 \mathrm{~g}, \mathrm{Mg}: 1 \mathrm{~g}$ & - & - & 11 (22\%) & $21(40 \%)$ \\
\hline \multirow[t]{2}{*}{ Dong et al. (35) } & Yes & $\begin{array}{l}\text { Double- } \\
\text { blind }\end{array}$ & $\mathrm{NCl}-\mathrm{CTC}$ & $\begin{array}{l}\text { Gastrointestinal } \\
\text { tract }\end{array}$ & Oxaliplatin & $\mathrm{Ca} / \mathrm{Mg}$ & 29 & Placebo & 31 & Ca: $1 \mathrm{~g}, \mathrm{Mg}: 1 \mathrm{~g}$ & $22(76 \%)$ & 27 (87\%) & $4(14 \%)$ & $11(35 \%)$ \\
\hline & & & & $\begin{array}{l}\text { Gastrointestinal } \\
\text { tract }\end{array}$ & Oxaliplatin & Glu & 33 & Placebo & 31 & Glu: $1,500 \mathrm{mg} / \mathrm{m}^{2}$ & 27 (82\%) & 27 (87\%) & $8(24 \%)$ & $11(35 \%)$ \\
\hline Ishibashi et al. (37) & Yes & $\begin{array}{l}\text { Double- } \\
\text { blind }\end{array}$ & $\mathrm{NCl}-\mathrm{CTC}$ & Colorectal & Oxaliplatin & $\mathrm{Ca} / \mathrm{Mg}$ & 17 & Placebo & 16 & Ca: 0.85 g, Mg: $0.72 \mathrm{~g}$ & $17(100 \%)$ & 15 (94\%) & $1(6 \%)$ & $1(6 \%)$ \\
\hline Chay et al. (2) & Yes & $\begin{array}{l}\text { Double- } \\
\text { blind }\end{array}$ & $\mathrm{NCl}-\mathrm{CTC}$ & Colorectal & Oxaliplatin & $\mathrm{Ca} / \mathrm{Mg}$ & 13 & Placebo & 14 & Ca: $1 \mathrm{~g}, \mathrm{Mg}: 1 \mathrm{~g}$ & $7(54 \%)$ & $10(71 \%)$ & $7(54 \%)$ & $7(50 \%)$ \\
\hline Knijn et al. (9) & No & NS & $\mathrm{NCl}-\mathrm{CTC}$ & Colorectal & Oxaliplatin & $\mathrm{Ca} / \mathrm{Mg}$ & 551 & No & 181 & $\begin{array}{l}\text { Ca: } 2.25 \text { mmol, Mg: } \\
4 \text { mmol, } 100 \mathrm{ml}\end{array}$ & 466 (85\%) & 166 (92\%) & 218 (40\%) & $81(45 \%)$ \\
\hline Loprinzi et al. (8) & Yes & $\begin{array}{l}\text { Double- } \\
\text { blind }\end{array}$ & $\mathrm{NCl}-\mathrm{CTC}$ & Colon & Oxaliplatin & $\mathrm{Ca} / \mathrm{Mg}$ & 237 & Placebo & 116 & $\begin{array}{l}\text { Ca: } 2 \text { or } 1 \mathrm{~g} / \text { day, Mg: } 2 \\
\text { or } 1 \mathrm{~g} / \text { day }\end{array}$ & - & - & $63(27 \%)$ & 31 (27\%) \\
\hline Gamelin et al. (10) & No & NS & $\mathrm{NCl}-\mathrm{CTC}$ & Colorectal & Oxaliplatin & $\mathrm{Ca} / \mathrm{Mg}$ & 96 & No & 65 & $\begin{array}{l}\text { Ca: } 1 \text { g/day, Mg: } 1 \mathrm{~g} / \\
\text { day }\end{array}$ & 19 (20\%) & 29 (45\%) & 20 (21\%) & $29(45 \%)$ \\
\hline Pace et al. (43) & Yes & $\begin{array}{l}\text { Double- } \\
\text { blind }\end{array}$ & NS & Lung, glioma & Cisplatin & VE & 17 & Placebo & 24 & VE: 400 mg/day & - & - & $1(6 \%)$ & $10(42 \%)$ \\
\hline Argyriou et al. (18) & Yes & $\begin{array}{l}\text { Single- } \\
\text { blind }\end{array}$ & WHO & Various & Cisplatin & VE & 16 & No & 19 & VE: 600 mg/day & 3 (19\%) & 11 (58\%) & $8(50 \%)$ & 7 (37\%) \\
\hline $\begin{array}{l}\text { Kottschade et al. } \\
\text { (39) }\end{array}$ & Yes & NS & $\mathrm{NCl}-\mathrm{CTC}$ & Various & Various $^{\mathrm{a}}$ & VE & 103 & Placebo & 104 & VE: 300 mg & - & - & 33 (32\%) & 27 (26\%) \\
\hline Pace et al. (17) & Yes & NS & WHO & Various & Cisplatin & VE & 13 & No & 14 & VE: 300 mg/day & $4(31 \%)$ & 12 (86\%) & - & - \\
\hline Cascinu et al. (12) & Yes & $\begin{array}{l}\text { Double- } \\
\text { blind }\end{array}$ & WHO & Ovarian & Cisplatin & Glu & 25 & Placebo & 25 & Glu: $1.5 \mathrm{~g} / \mathrm{m}^{2}$ & $0(0 \%)$ & 16 (64\%) & $1(4 \%)$ & $13(52 \%)$ \\
\hline Cascinu et al. (13) & Yes & $\begin{array}{l}\text { Double- } \\
\text { blind }\end{array}$ & $\mathrm{NCl}-\mathrm{CTC}$ & Colorectal & Oxaliplatin & Glu & 26 & Placebo & 26 & Glu: $1.5 \mathrm{~g} / \mathrm{m}^{2}$ & $9(35 \%)$ & 15 (58\%) & $3(12 \%)$ & $8(31 \%)$ \\
\hline Milla et al. (42) & Yes & NS & $\mathrm{NCl}-\mathrm{CTC}$ & Colorectal & Oxaliplatin & Glu & 14 & Placebo & 13 & Glu: $1,500 \mathrm{mg} / \mathrm{m}^{2}$ & 14 (100\%) & 13 (100\%) & 7 (50\%) & $13(100 \%)$ \\
\hline Liu et al. (41) & Yes & NS & Oss & Colorectal & Oxaliplatin & Glu & 54 & Placebo & 51 & Glu: $1.9 \mathrm{~g} /$ day & 37 (69\%) & 46 (90\%) & 10 (19\%) & $16(31 \%)$ \\
\hline $\mathrm{Li}(40)$ & Yes & NS & OsS & NS & Oxaliplatin & Glu & 40 & Placebo & 40 & Glu: $1,200 \mathrm{mg} / \mathrm{d}$ & 3 (8\%) & 21 (53\%) & $2(5 \%)$ & 11 (28\%) \\
\hline Smyth et al. (44) & Yes & No & $\mathrm{NCl}-\mathrm{CTC}$ & Ovarian & Cisplatin & Glu & 74 & Placebo & 77 & Glu: $3 \mathrm{~g} / \mathrm{m}^{2}$ & 29 (39\%) & 36 (47\%) & $2(3 \%)$ & $2(3 \%)$ \\
\hline Gallardo et al. (36) & Yes & $\begin{array}{l}\text { Single- } \\
\text { blind }\end{array}$ & $\mathrm{NCl}-\mathrm{CTC}$ & Cervical & Cisplatin & Ami & 10 & No & 10 & Ami: 825 mg/m² & - & - & $1(10 \%)$ & $4(40 \%)$ \\
\hline
\end{tabular}


TABLE 2 | Direct pairwise comparison results of neurotoxicity treatments.

\begin{tabular}{lcc}
\hline Comparison & Overall neurotoxicity & Severe neurotoxicity \\
\hline Ca/Mg vs. placebo & $0.86(0.70,1.06)$ & $1.55(1.27,1.91)$ \\
Glutathione vs. placebo & $\mathbf{0 . 6 4}(\mathbf{0 . 4 7}, \mathbf{0 . 8 6})$ & $\mathbf{0 . 4 2}(\mathbf{0 . 2 7}, \mathbf{0 . 6 7})$ \\
Glutathione vs. Ca/Mg & $1.01(0.45,2.26)$ & $1.63(0.43,6.14)$ \\
Vitamin E vs. placebo & $\mathbf{0 . 3 4}(\mathbf{0 . 1 2}, \mathbf{0 . 9 1})$ & $0.84(0.51,1.40)$ \\
Amifostine vs. placebo & $\mathbf{0 . 7 3}(\mathbf{0 . 5 4}, \mathbf{0 . 9 9})$ & $\mathbf{0 . 5 3}(\mathbf{0 . 3 7}, \mathbf{0 . 7 8 )}$ \\
Amifostine vs. glutathione & $\mathbf{0 . 1 4}(\mathbf{0 . 0 5 , 0 . 3 6 )}$ & $\mathbf{0 . 1 1}(\mathbf{0 . 0 1}, \mathbf{0 . 9 1})$ \\
\hline
\end{tabular}

Bold font indicates statistically significant difference.

The data are odds ratio and $95 \%$ confidence interval.

${ }^{a}$ Grade $\geq 2$.

TABLE 3 | The surface under cumulative ranking curve results of neurotoxicity treatments.

\begin{tabular}{lcc}
\hline Treatment & Overall neurotoxicity & Severe $^{\text {neurotoxicity }}$ \\
\hline Placebo & 0.060 & 0.062 \\
Ca/Mg & 0.375 & 0.365 \\
Glutathione & 0.425 & 0.710 \\
Amifostine & 0.822 & 0.855 \\
Vitamin E & 0.822 & 0.507
\end{tabular}

${ }^{a}$ Grade $\geq 2$.

CI: $0.12-0.91$ and amifostine: $\mathrm{OR}=0.73$, 95\% CI: 0.54-0.99). Furthermore, amifostine appears to be superior to glutathione in decreasing the risk of overall neurotoxicity $(\mathrm{OR}=0.14,95 \%$ $\mathrm{CI}=0.05-0.36)$. As an NMA combines both direct and indirect evidence, the results are similar but not exactly the same (Table 3 and Figure 2). Patients treated with amifostine or VE exhibited a significantly lower risk of overall neurotoxicity than those treated with the placebo (amifostine: $\mathrm{OR}=0.10,95 \% \mathrm{CrI}$ : 0.02-0.46; VE: $\mathrm{OR}=0.08$, 95\% CrI: 0.01-0.99).

\section{Severe Neurotoxicity}

The direct comparison results with respect to the risk of severe neurotoxicity are displayed in Table 2. Patients treated with glutathione or amifostine exhibited a significantly reduced risk of severe neurotoxicity compared with those treated with the placebo (glutathione: $\mathrm{OR}=0.42,95 \% \mathrm{CI}$ : 0.27-0.67; amifostine: $\mathrm{OR}=0.53,95 \% \mathrm{CI}: 0.37-0.78)$. Moreover, patients treated with amifostine appear to have a lower risk of severe neurotoxicity than those treated with glutathione $(\mathrm{OR}=0.11,95 \% \mathrm{CI}$ : $0.01-0.91)$. The corresponding NMA results are presented in Table 4 and Figure 2: glutathione and amifostine present notable superiority compared to the placebo in preventing severe neurotoxicity (glutathione: $\mathrm{OR}=0.19,95 \%$ CrI: 0.04-0.64; amifostine: $\mathrm{OR}=0.12,95 \% \mathrm{CrI}$ : 0.02-0.48).

\section{Consistency and Conformity Assessment}

The node splitting method was used to assess the consistency of direct and indirect evidence (Figure 3). A $P$-value of $<0.05$ indicates a significant inconsistency between direct and indirect evidence. A significant inconsistency with respect to the risk of overall neurotoxicity was detected in the comparison between glutathione and placebo, amifostine and placebo, and amifostine and glutathione. No significant inconsistency was observed in the comparisons with respect to the risk of severe neurotoxicity. We also produced heat plots in order to assess the conformity of 


\section{Overall Neurotoxicity}

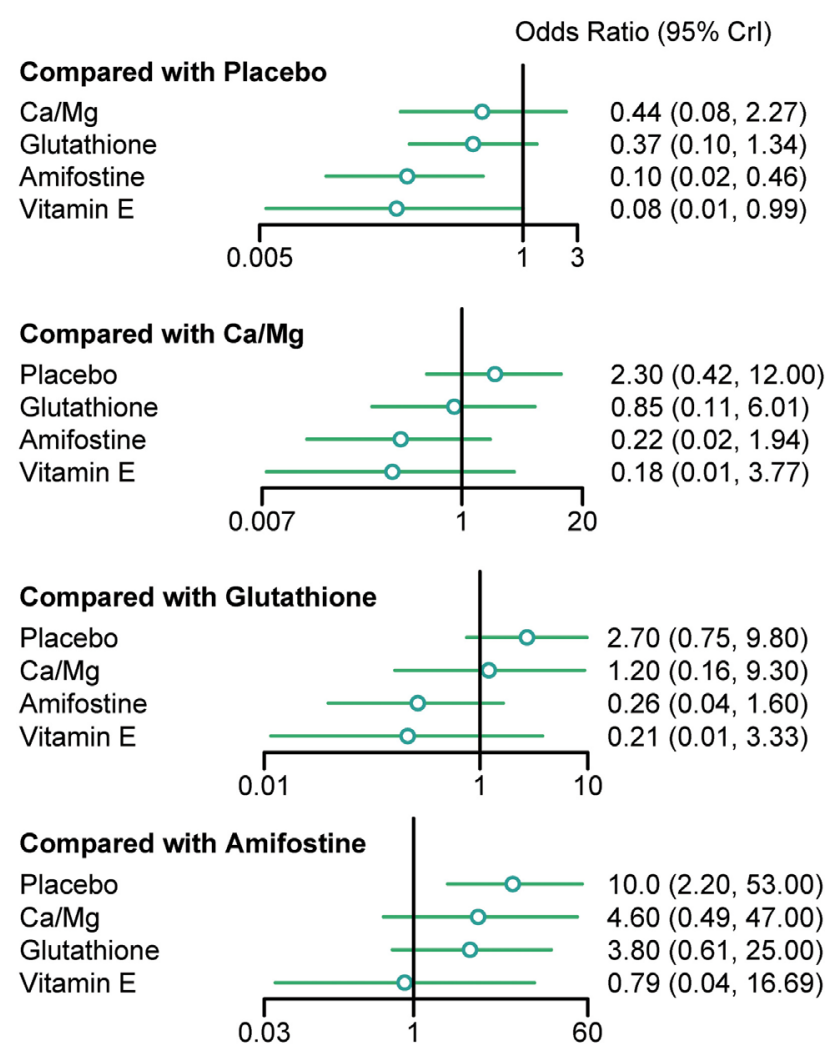

\section{Compared with Vitamin E}

Placebo

$\mathrm{Ca} / \mathrm{Mg}$

Glutathione

Amifostine

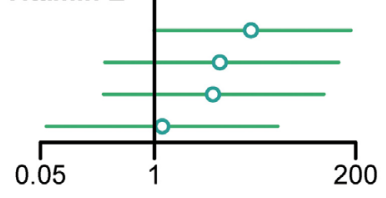

$13.0(0.99,180.00)$

$5.60(0.27,130.00)$

$4.70(0.26,87.00)$

$1.20(0.06,26.00)$

\section{Severe Neurotoxicity}

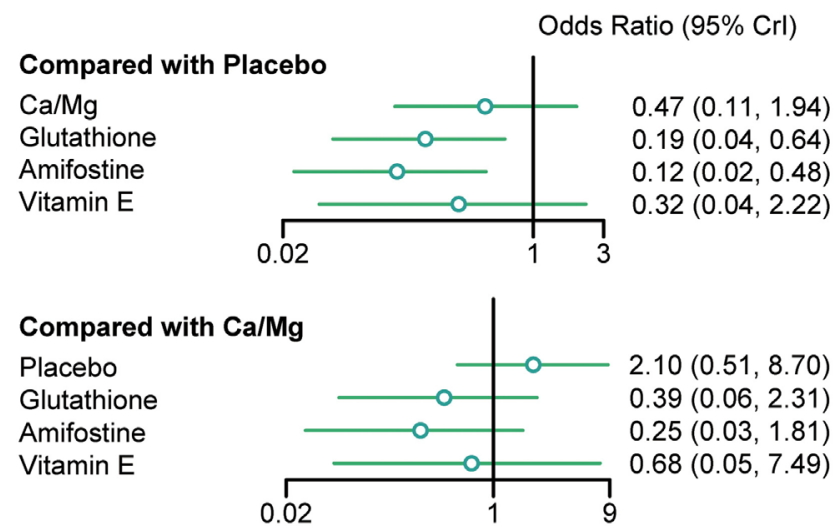

\section{Compared with Glutathione}

Placebo

$\mathrm{Ca} / \mathrm{Mg}$

Amifostine

Vitamin E

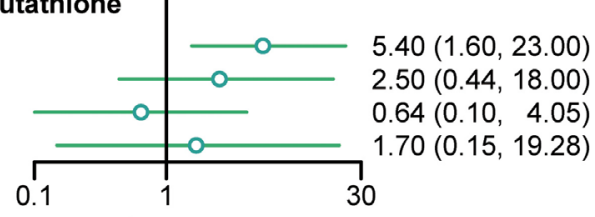

Compared with Amifostine

Placebo

$\mathrm{Ca} / \mathrm{Mg}$

Glutathione

Vitamin E

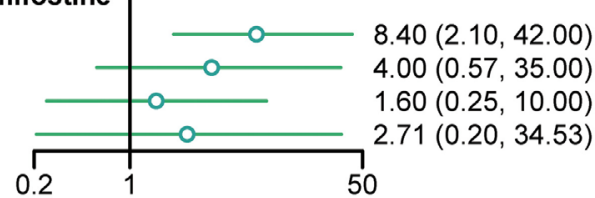

Compared with Vitamin E

Placebo

$\mathrm{Ca} / \mathrm{Mg}$

Glutathione

Amifostine

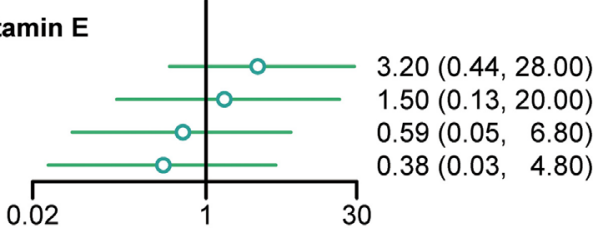

FIGURE 2 | Odds ratios (95\% credential intervals) for network comparison of neurotoxicity treatments.

TABLE 4 | Network meta-analysis results of neurotoxicity treatments.

\begin{tabular}{|c|c|c|c|c|c|}
\hline Severe neurotoxicity ${ }^{a}$ & \multicolumn{5}{|c|}{ Overall neurotoxicity } \\
\hline & $0.47(0.11,1.94)$ & $\mathrm{Ca} / \mathrm{Mg}$ & $0.85(0.11,6.01)$ & $0.22(0.02,1.94)$ & $0.18(0.01,3.77)$ \\
\hline & $0.19(0.04,0.64)$ & $0.39(0.06,2.31)$ & Glutathione & $0.26(0.04,1.60)$ & $0.21(0.01,3.33)$ \\
\hline & $0.12(0.02,0.48)$ & $0.25(0.03,1.81)$ & $0.64(0.10,4.05)$ & Amifostine & $0.79(0.04,16.69)$ \\
\hline & $0.32(0.04,2.22)$ & $0.68(0.05,7.49)$ & $1.70(0.15,19.28)$ & $2.71(0.20,34.53)$ & Vitamin E \\
\hline
\end{tabular}

Bold font indicates statistically significant difference and nothing special about the gray shade.

${ }^{a}$ Grade $\geq 2$.

direct and indirect evidence (Figure 4). A deeper color indicates a higher inconsistency. A significant inconsistency in overall neurotoxicity was found in the comparisons of glutathione and placebo, amifostine and placebo, and amifostine and glutathione. No significant inconsistency was observed in the comparisons for severe neurotoxicity.

\section{Ranking and Cluster Analysis}

The corresponding rank of each intervention was determined basing on their SUCRA value (Table 4 and Figure 5). A higher SUCRA indicates a greater efficacy. Amifostine and VE proved to be the 2 most preferable treatments with respect to overall neurotoxicity (SUCRA $=0.82$ for both), while amifostine with 


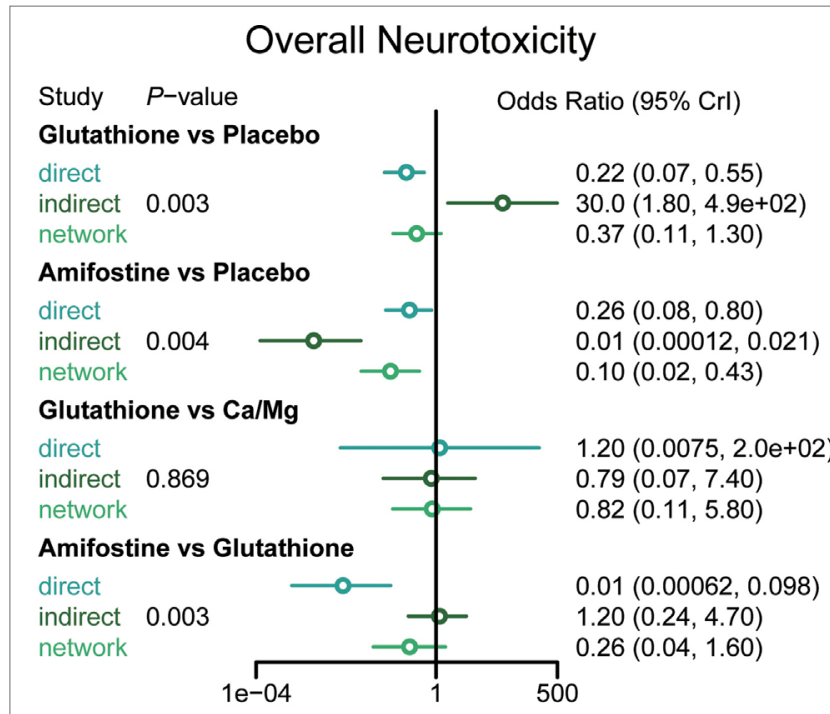

Severe Neurotoxicity

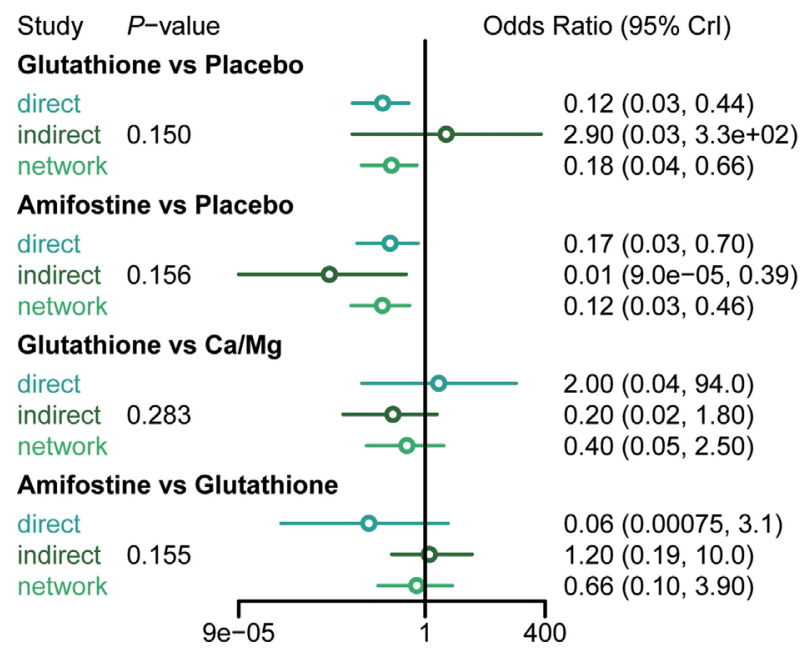

FIGURE 3 | Node splitting results according to type of interventions for all clinical outcomes.

the highest SUCRA of 0.86 was the top choice for severe neurotoxicity. We also attempted to categorize the five interventions (placebo, $\mathrm{Ca} / \mathrm{Mg}$, glutathione, $\mathrm{VE}$, and amifostine) using a cluster analysis (Figure 6). In the cluster analysis plot, treatments were set as points according to their SUCRA values regarding axis events. Amifostine scored best in terms of both overall and severe neurotoxicity.

\section{Publication Bias}

We conducted an assessment of publication bias using funnel plots (Figure S2 in Supplementary Material). According to the symmetrical distribution of the points (where each point denotes a corresponding involved study), no evidence of publication bias was observed for both overall and severe neurotoxicity.

\section{DISCUSSION}

\section{Primary Findings}

A systematic analysis was performed in order to determine the best therapeutic intervention for CICNT in cancer patients. The efficacy of different treatments was evaluated based on their ability to prevent overall and severe neurotoxicity. The overall neurotoxicity network comparison results demonstrated that amifostine and VE both have significantly lower OR values compared to the placebo, indicating a high efficacy. In regard to preventing severe neurotoxicity, glutathione and amifostine exhibited superiority. The SUCRA and cluster plot outcomes of the five interventions (including the placebo as a control) also provided us with useful information. They demonstrated that amifostine and VE were the two top recommended interventions for overall neurotoxicity and amifostine and glutathione were favored for severe neurotoxicity. Thus, we could confidently conclude that amifostine and VE should be recommended in treating overall neuropathy and that amifostine and glutathione should be recommended to treat severe neurotoxicity. Amifostine is our top recommendation for treating neurotoxicity. The excellent performance of amifostine in treating CICNT may come from its ability to eliminate the harmful oxidants derived from the interaction of oxygen radicals and neurotoxicity-related DNA groups. It does this by competing with oxygen or oxygen radicals for the binding to DNA groups. This mechanism is similar to the function of endogenous thiol (45). Furthermore, due to the intracellular micro-environmental difference between normal and tumor cells, amifostine can be absorbed into normal cells (46) and have a protective effect.

\section{Direct and Indirect Evidence in this Study}

An NMA synthesizes non-conclusive evidence from clinical trials to construct a network which compares multiple treatments simultaneously. This network is mainly based on direct evidence; indirect evidence is obtained by forming opinions on related direct evidence. Each treatment involved in the NMA would be compared using both direct and indirect evidence or just indirect evidence. However, a limitation of NMA is that there can be significant incoherence between direct and indirect comparisons (referred to as inconsistency) (47). The results of the node splitting and heat plots revealed that the direct comparison results of amifostine and glutathione against the placebo significantly deviated from the corresponding indirect comparison results. The comparison between amifostine and glutathione also displayed a striking inconsistency between the two types of evidence. This may be due to the limited direct comparison evidence we were able to obtain on amifostine and glutathione (only 1 included study with only 46 patients in each group) (15). However, the direct and indirect evidence of other intervention comparisons were consistent and validate the consistency model applied in this NMA.

\section{Consistencies and Discrepancies with Other Studies}

Our result that amifostine is extremely effective in treating both overall and severe neurotoxicity is supported by the findings of various clinical trials $(14,16,36)$. However, there is one exception 

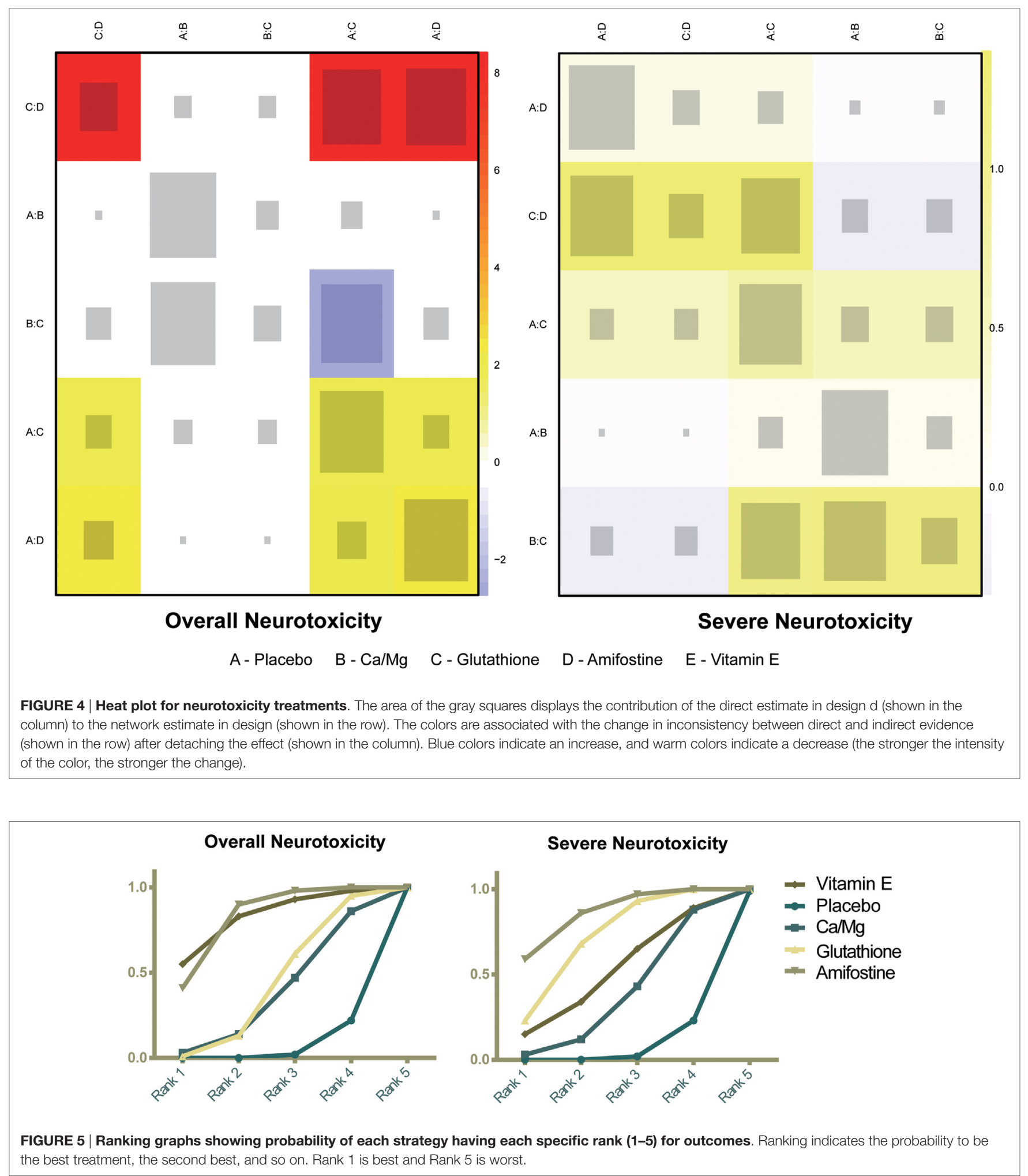

that reports that amifostine is not able to have a preventive role in neuropathy (38). This inconsistency may result from the relatively small sample size (19) and special type of chemotherapy (carboplatin and paclitaxel) used in the study. Most previous studies reported that the neuroprotective ability of $\mathrm{VE}$ can protect cancer patients from experiencing chemotherapy-induced neurotoxicity effectively and safely $(17,18,43)$. In this study, VE also showed superiority in preventing overall neurotoxicity (though with a 


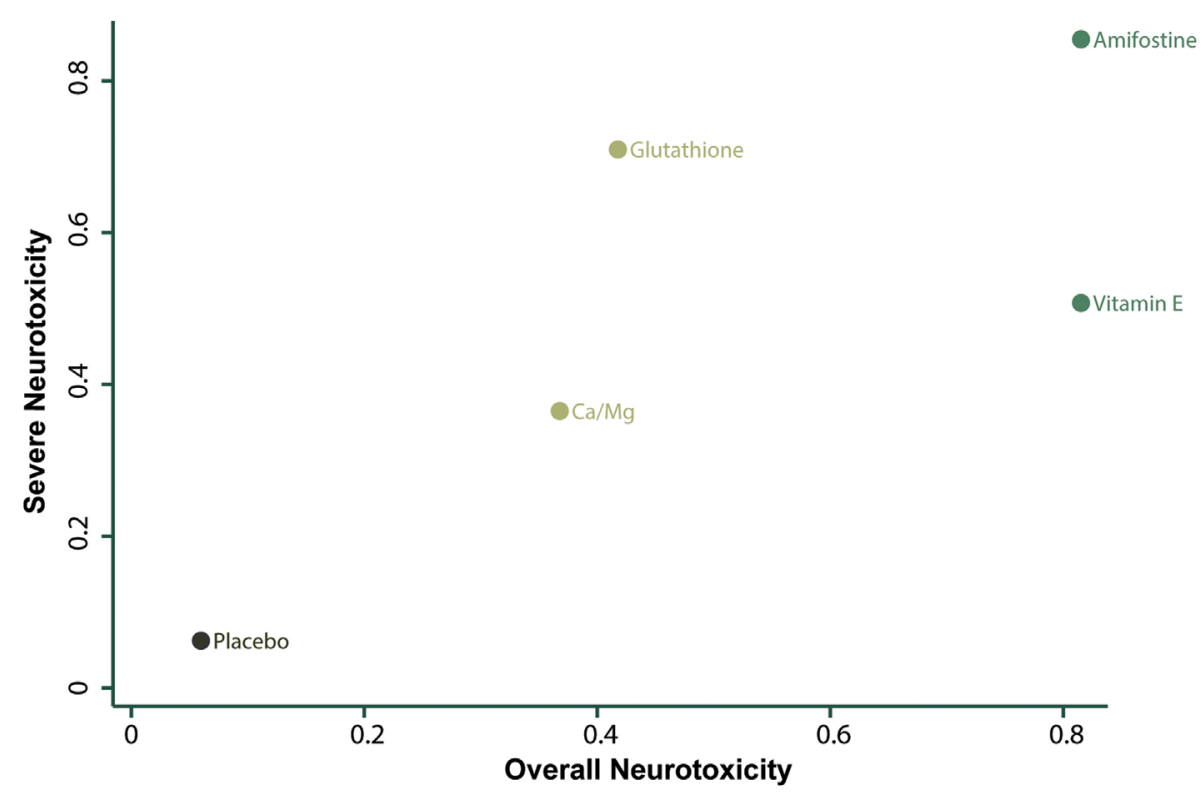

FIGURE 6 | Cluster analysis.

considerably large 95\% CrI). Glutathione is another intervention suggested to be a protective intervention for chemotherapyinduced neurotoxicity. We found that glutathione had above average efficacy in reducing severe neurotoxicity. This result is also emphasized in other studies $(12,13)$. The inner mechanism of its ability to weaken neurotoxicity is believed to be a function of the thionucleophilic region located inside the glutathione. Its high heavy metal-binding ability enables it to prevent the accumulation of platinum (7). Calcium and magnesium infusion $(\mathrm{Ca} / \mathrm{Mg})$ is the most popular regimen used to prevent and treat neurotoxicity. However, its real efficacy still remains disputed. Individual trials conducted over the last few years imply that it is an effective intervention for dealing with oxaliplatin-induced cumulative neurotoxicity in colon cancer (11) and that it can also reduce the probability of all-grade neurotoxicity (9). Furthermore, the efficacy of $\mathrm{Ca} / \mathrm{Mg}$ has been verified by a number of MA studies. For example, one such study concluded that subjects treated with $\mathrm{Ca} / \mathrm{Mg}$ displayed a significantly decreased risk of developing both grade 1 and grade 2 oxaliplatin-induced neurotoxicity (21). Another MA study had a similar conclusion (22), reporting that $\mathrm{Ca} / \mathrm{Mg}$ tends to lower the incidence of oxaliplatin-induced acute and cumulative neurotoxicity without remarkably altering the validity of chemotherapy. On the other hand, some studies $(2,8)$ indicated that $\mathrm{Ca} / \mathrm{Mg}$ had no significantly higher efficacy compared to the placebo. In fact, as no remarkable difference was detected between the $\mathrm{Ca} / \mathrm{Mg}$ and placebo groups, this study also did not support the efficacy of $\mathrm{Ca} / \mathrm{Mg}$. The application of $\mathrm{Ca} / \mathrm{Mg}$ may be not as ideal and further study is required.

\section{Advantages and Limitations}

No previous MA study has recommended the ideal treatment for CICNT. However, through the application of an NMA, this research makes a systematic simultaneous comparison of multiple treatments and makes a recommendation on the ideal treatment. Both direct and indirect evidence contributed to comprehensively assessing the effectiveness of each drug. There is often a lack of direct evidence between active interventions and this limits further drug evaluation. However, this can be remedied by an NMA by utilizing indirect comparisons. Most of the research involved in this study made comparisons between a certain drug and the placebo (only one compared amifostine and glutathione directly). However, by constructing a network that connects all interventions with the supplement of indirect evidence, we were able to compare the relative efficacy between any two interventions.

Nevertheless, there are still some limitations of this study. First, this NMA only included 23 studies and this relatively small study size had a considerable width of $95 \% \mathrm{CrI}$ in some drugs (VE). Therefore, there was a large variance in the amount of data related to different interventions. The recent clinical trials conducted on CICNT are also very limited. $\mathrm{Ca} / \mathrm{Mg}$ has long been used as a common CICNT treatment. If our NMA included more studies, the results could be more representative and powerful. Second, during the process of literature review and data extraction, we noted that there were various standards of neurotoxicity assessment such as the NCI-CTC (31), WHO Criteria (32), and the OSS (33). This inconsistency in evaluating criteria for neurotoxicity, along with the differences in patient background such as tumor types, stage, and type of chemotherapy received can skew results.

\section{Prospect}

Much research regarding the ideal treatment for CICNT is required. In this study, we defined a neurotoxicity of above grade 
0 as overall neurotoxicity and above grade 2 as severe neurotoxicity. However, in a practical clinical situation, the average danger of overall and severe neurotoxicity is much different. This suggests that different corresponding weights should be considered in NMAs to give a more realistic recommendation (48). In addition, as a result of insufficient data in the included studies, we were unable to conduct an analysis of the safety characteristics of each drug. Further studies concerning the safety of each treatment is required.

\section{CONCLUSION}

Current clinical studies and MAs have not yet determined one effective and practical intervention for CICNT. Our NMA aimed to reveal the ideal regimen of CICNT treatment. Amifostine is our top recommendation as it has the highest efficacy for both overall and severe neurotoxicities. The second choice for treating severe neurotoxicity is glutathione and VE for overall neurotoxicity. As we were limited by data, we did not compare the safety outcome of each therapy; therefore, there is still an urgent need for future research.

\section{REFERENCES}

1. Park SB, Goldstein D, Krishnan AV, Lin CS, Friedlander ML, Cassidy J, et al. Chemotherapy-induced peripheral neurotoxicity: a critical analysis. $C A$ Cancer J Clin (2013) 63:419-37. doi:10.3322/caac.21204

2. Chay WY, Tan SH, Lo YL, Ong SY, Ng HC, Gao F, et al. Use of calcium and magnesium infusions in prevention of oxaliplatin induced sensory neuropathy. Asia Pac J Clin Oncol (2010) 6:270-7. doi:10.1111/j.1743-7563.2010.01344.x

3. de Gramont A, Figer A, Seymour M, Homerin M, Hmissi A, Cassidy J, et al. Leucovorin and fluorouracil with or without oxaliplatin as first-line treatment in advanced colorectal cancer. J Clin Oncol (2000) 18:2938-47. doi:10.1200/ jco.2000.18.16.2938

4. Cersosimo RJ. Oxaliplatin-associated neuropathy: a review. Ann Pharmacother (2005) 39:128-35. doi:10.1345/aph.1E319

5. Gamelin E, Gamelin L, Bossi L, Quasthoff S. Clinical aspects and molecular basis of oxaliplatin neurotoxicity: current management and development of preventive measures. Semin Oncol (2002) 29:21-33. doi:10.1053/ sonc. 2002.35525

6. Grolleau F, Gamelin L, Boisdron-Celle M, Lapied B, Pelhate M, Gamelin E. A possible explanation for a neurotoxic effect of the anticancer agent oxaliplatin on neuronal voltage-gated sodium channels. J Neurophysiol (2001) 85:2293-7.

7. Albers JW, Chaudhry V, Cavaletti G, Donehower RC. Interventions for preventing neuropathy caused by cisplatin and related compounds. Cochrane Database Syst Rev (2014) 31:CD005228. doi:10.1002/14651858.CD005228. pub4

8. Loprinzi CL, Qin R, Dakhil SR, Fehrenbacher L, Flynn KA, Atherton P, et al. Phase III randomized, placebo-controlled, double-blind study of intravenous calcium and magnesium to prevent oxaliplatin-induced sensory neurotoxicity (N08CB/Alliance). J Clin Oncol (2014) 32:997-1005. doi:10.1200/ jco.2013.52.0536

9. Knijn N, Tol J, Koopman M, Werter MJ, Imholz AL, Valster FA, et al. The effect of prophylactic calcium and magnesium infusions on the incidence of neurotoxicity and clinical outcome of oxaliplatin-based systemic treatment in advanced colorectal cancer patients. Eur J Cancer (2011) 47:369-74. doi:10.1016/j.ejca.2010.10.006

10. Gamelin L, Boisdron-Celle M, Delva R, Guerin-Meyer V, Ifrah N, Morel A, et al. Prevention of oxaliplatin-related neurotoxicity by calcium and magnesium infusions: a retrospective study of 161 patients receiving oxaliplatin combined with 5-fluorouracil and leucovorin for advanced colorectal cancer. Clin Cancer Res (2004) 10:4055-61. doi:10.1158/1078-0432.CCR-03-0666

\section{AUTHOR CONTRIBUTIONS}

Conception and design: WY. Acquisition of data and analysis and interpretation of data: XF, HW, and JL. Drafting the article: XF, CW, LM, and QM. Critically revising the article: CW, LM, and QM. Administrative/technical/material support: WY.

\section{FUNDING}

This research was supported by the Project of Precision Medicine for Neurological disorders in Jilin Province.

\section{SUPPLEMENTARY MATERIAL}

The Supplementary Material for this article can be found online at http://journal.frontiersin.org/article/10.3389/fneur.2017.00223/ full\#supplementary-material.

FIGURE S1 | Literature flowchart.

FIGURE S2 | Publication bias

TABLE S1 | Jadad scale of 23 included studies.

11. Grothey A, Nikcevich DA, Sloan JA, Kugler JW, Silberstein PT, Dentchev T, et al. Intravenous calcium and magnesium for oxaliplatin-induced sensory neurotoxicity in adjuvant colon cancer: NCCTG N04C7. J Clin Oncol (2011) 29:421-7. doi:10.1200/jco.2010.31.5911

12. Cascinu S, Cordella L, Del Ferro E, Fronzoni M, Catalano G. Neuroprotective effect of reduced glutathione on cisplatin-based chemotherapy in advanced gastric cancer: a randomized double-blind placebo-controlled trial. JClin Oncol (1995) 13:26-32. doi:10.1200/JCO.1995.13.1.26

13. Cascinu S, Catalano V, Cordella L, Labianca R, Giordani P, Baldelli AM, et al. Neuroprotective effect of reduced glutathione on oxaliplatin-based chemotherapy in advanced colorectal cancer: a randomized, double-blind, placebo-controlled trial. JClin Oncol (2002) 20:3478-83. doi:10.1200/ JCO.2002.07.061

14. Kemp G, Rose P, Lurain J, Berman M, Manetta A, Roullet B, et al. Amifostine pretreatment for protection against cyclophosphamide-induced and cisplatin-induced toxicities: results of a randomized control trial in patients with advanced ovarian cancer. JClin Oncol (1996) 14:2101-12. doi:10.1200/ jco.1996.14.7.2101

15. Lu P, Fan QX, Wang LX, Wang X, Zong H, Wang RL. [Prophylactic effect of amifostine on oxaliplatin-related neurotoxicity in patients with digestive tract tumors]. Ai Zheng (2008) 27:1117-20.

16. De Vos FY, Bos AM, Schaapveld M, de Swart CA, de Graaf H, van der Zee AG, et al. A randomized phase II study of paclitaxel with carboplatin \pm amifostine as first line treatment in advanced ovarian carcinoma. Gynecol Oncol (2005) 97:60-7. doi:10.1016/j.ygyno.2004.11.052

17. Pace A, Savarese A, Picardo M, Maresca V, Pacetti U, Del Monte G, et al. Neuroprotective effect of vitamin E supplementation in patients treated with cisplatin chemotherapy. JClin Oncol (2003) 21:927-31. doi:10.1200/ JCO.2003.05.139

18. Argyriou AA, Chroni E, Koutras A, Iconomou G, Papapetropoulos S, Polychronopoulos $\mathrm{P}$, et al. A randomized controlled trial evaluating the efficacy and safety of vitamin E supplementation for protection against cisplatin-induced peripheral neuropathy: final results. Support Care Cancer (2006) 14:1134-40. doi:10.1007/s00520-006-0072-3

19. Turtle MJ, Cullen P, Prys-Roberts C, Coates D, Monk CR, Faroqui MH. Dose requirements of propofol by infusion during nitrous oxide anaesthesia in man. II: patients premedicated with lorazepam. Br J Anaesth (1987) 59:283-7. doi:10.1093/bja/59.3.283

20. Wu Z, Ouyang J, He Z, Zhang S. Infusion of calcium and magnesium for oxaliplatin-induced sensory neurotoxicity in colorectal cancer: a systematic 
review and meta-analysis. Eur J Cancer (2012) 48:1791-8. doi:10.1016/j. ejca.2012.03.018

21. Xu XT, Dai ZH, Xu Q, Qiao YQ, Gu Y, Nie F, et al. Safety and efficacy of calcium and magnesium infusions in the chemoprevention of oxaliplatin-induced sensory neuropathy in gastrointestinal cancers. J Dig Dis (2013) 14:288-98. doi:10.1111/1751-2980.12050

22. Wen F, Zhou Y, Wang W, Hu QC, Liu YT, Zhang PF, et al. Ca/Mg infusions for the prevention of oxaliplatin-related neurotoxicity in patients with colorectal cancer: a meta-analysis. Ann Oncol (2013) 24:171-8. doi:10.1093/annonc/ $\mathrm{mds} 211$

23. Ao R, Wang YH, Li RW, Wang ZR. Effects of calcium and magnesium on acute and chronic neurotoxicity caused by oxaliplatin: a meta-analysis. Exp Ther Med (2012) 4:933-7. doi:10.3892/etm.2012.678

24. Albers JW, Chaudhry V, Cavaletti G, Donehower RC. Interventions for preventing neuropathy caused by cisplatin and related compounds. Cochrane Database Syst Rev (2011) 16:CD005228. doi:10.1002/14651858.CD005228. pub3

25. Garipagaoglu M, Kayikçioglu F, Köse MF, Adli M, Gülkesen KH, Koçak Z, et al. Adding concurrent low dose continuous infusion of cisplatin to radiotherapy in locally advanced cervical carcinoma: a prospective randomized pilot study. Br J Radiol (2004) 77:581-7. doi:10.1259/bjr/63967203

26. Salanti G, Higgins JP, Ades AE, Ioannidis JP. Evaluation of networks of randomized trials. Stat Methods Med Res (2008) 17:279-301. doi:10.1177/0962280207080643

27. Sun F, Wu S, Guo S, Yu K, Yang Z, Li L, et al. Effect of GLP-1 receptor agonists on waist circumference among type 2 diabetes patients: a systematic review and network meta-analysis. Endocrine (2015) 48:794-803. doi:10.1007/ s12020-014-0373-0

28. Cipriani A, Barbui C, Salanti G, Rendell J, Brown R, Stockton S, et al. Comparative efficacy and acceptability of antimanic drugs in acute mania: a multiple-treatments meta-analysis. Lancet (2011) 378:1306-15. doi:10.1016/ S0140-6736(11)60873-8

29. Fujii T, Le Du F, Xiao L, Kogawa T, Barcenas CH, Alvarez RH, et al. Effectiveness of an adjuvant chemotherapy regimen for early-stage breast cancer: a systematic review and network meta-analysis. JAMA Oncol (2015) 1:1311-8. doi:10.1001/jamaoncol.2015.3062

30. Yan M, Kumachev A, Siu LL, Chan KK. Chemoradiotherapy regimens for locoregionally advanced nasopharyngeal carcinoma: a Bayesian network meta-analysis. Eur J Cancer (2015) 51:1570-9. doi:10.1016/j.ejca. 2015.04.027

31. Alberti P, Rossi E, Cornblath DR, Merkies IS, Postma TJ, Frigeni B, et al. Physician-assessed and patient-reported outcome measures in chemotherapy-induced sensory peripheral neurotoxicity: two sides of the same coin. Ann Oncol (2014) 25:257-64. doi:10.1093/annonc/mdt409

32. Yoon J, Jeon JH, Lee YW, Cho CK, Kwon KR, Shin JE, et al. Sweet bee venom pharmacopuncture for chemotherapy-induced peripheral neuropathy. J Acupunct Meridian Stud (2012) 5:156-65. doi:10.1016/j.jams.2012.05.003

33. Kautio AL, Haanpaa M, Kautiainen H, Leminen A, Kalso E, Saarto T. Oxaliplatin scale and National Cancer Institute-common toxicity criteria in the assessment of chemotherapy-induced peripheral neuropathy. Anticancer Res (2011) 31:3493-6.

34. Chen X, Wang Y, Lou J. Clinical study of amifostine for preventing oxaliplatin-induced neurotoxicity. China Pharm (2011) (7):76-7.

35. Dong M, Xing PY, Liu P, Feng FY, Shi YK. [Assessment of the protective effect of calcium-magnesium infusion and glutathione on oxaliplatin-induced neurotoxicity]. Zhonghua Zhong Liu Za Zhi (2010) 32:208-11.

36. Gallardo D, Mohar A, Calderillo G, Mota A, Solorza G, Lozano A, et al. Cisplatin, radiation, and amifostine in carcinoma of the uterine cervix. Int J Gynecol Cancer (1999) 9:225-30. doi:10.1046/j.1525-1438.1999.99029.x
37. Ishibashi K, Okada N, Miyazaki T, Sano M, Ishida H. Effect of calcium and magnesium on neurotoxicity and blood platinum concentrations in patients receiving mFOLFOX6 therapy: a prospective randomized study. Int J Clin Oncol (2010) 15:82-7. doi:10.1007/s10147-009-0015-3

38. Kanat O, Evrensel T, Baran I, Coskun H, Zarifoglu M, Turan OF, et al. Protective effect of amifostine against toxicity of paclitaxel and carboplatin in non-small cell lung cancer: a single center randomized study. Med Oncol (2003) 20:237-45. doi:10.1385/MO:20:3:237

39. Kottschade LA, Sloan JA, Mazurczak MA, Johnson DB, Murphy BP, Rowland KM, et al. The use of vitamin $\mathrm{E}$ for the prevention of chemotherapyinduced peripheral neuropathy: results of a randomized phase III clinical trial. Support Care Cancer (2011) 19:1769-77. doi:10.1007/s00520-010-1018-3

40. Li Y. Observation of clinical effect of glutathione on prevention of neurotoxicity induced by oxaliplatin. Chinese J Mod Drug Appl (2014):143-4.

41. Liu S, Wei P, Zhang L, Gao X, Tian Y, Lu H, et al. Clinical study of the protective effect of reduced glutathion on oxaliplatin-induced chronic neurotoxicity. China Pract Med (2011):5-6. doi:10.14163/j.cnki.11-5547/r.2011.02.228

42. Milla P, Airoldi M, Weber G, Drescher A, Jaehde U, Cattel L. Administration of reduced glutathione in FOLFOX4 adjuvant treatment for colorectal cancer: effect on oxaliplatin pharmacokinetics, Pt-DNA adduct formation, and neurotoxicity. Anticancer Drugs (2009) 20:396-402. doi:10.1097/ CAD.0b013e32832a2dc1

43. Pace A, Giannarelli D, Galiè E, Savarese A, Carpano S, Della Giulia M, et al. Vitamin e neuroprotection for cisplatin neuropathy: a randomized, placebo-controlled trial. Neurology (2010) 74:762-6. doi:10.1212/WNL. 0b013e3181d5279e

44. Smyth JF, Bowman A, Perren T, Wilkinson P, Prescott RJ, Quinn KJ, et al. Glutathione reduces the toxicity and improves quality of life of women diagnosed with ovarian cancer treated with cisplatin: results of a double-blind, randomised trial. Ann Oncol (1997) 8:569-73. doi:10.1023/A:1008211226339

45. van der Vijgh WJ, Korst AE. Amifostine (Ethyol): pharmacokinetic and pharmacodynamic effects in vivo. Eur J Cancer (1996) 32A(Suppl 4):S26-30. doi:10.1016/S0959-8049(96)00332-2

46. Culy CR, Spencer CM. Amifostine: an update on its clinical status as a cytoprotectant in patients with cancer receiving chemotherapy or radiotherapy and its potential therapeutic application in myelodysplastic syndrome. Drugs (2001) 61:641-84. doi:10.2165/00003495-200161050-00012

47. Giacoppo D, Gargiulo G, Aruta P, Capranzano P, Tamburino C, Capodanno D. Treatment strategies for coronary in-stent restenosis: systematic review and hierarchical Bayesian network meta-analysis of 24 randomised trials and 4880 patients. BMJ (2015) 351:h5392. doi:10.1136/bmj.h5392

48. Alfirevic Z, Keeney E, Dowswell T, Welton NJ, Dias S, Jones LV, et al. Labour induction with prostaglandins: a systematic review and network metaanalysis. $B M J$ (2015) 350:h217. doi:10.1136/bmj.h217

Conflict of Interest Statement: The authors declare that the research was conducted in the absence of any commercial or financial relationships that could be construed as a potential conflict of interest.

The reviewer, DM, and handling editor declared their shared affiliation and the handling editor states that the process nevertheless met the standards of a fair and objective review.

Copyright (๑) $2017 \mathrm{Fu}, \mathrm{Wu}, \mathrm{Li}$, Wang, Li, Ma and Yang. This is an open-access article distributed under the terms of the Creative Commons Attribution License (CC BY). The use, distribution or reproduction in other forums is permitted, provided the original author(s) or licensor are credited and that the original publication in this journal is cited, in accordance with accepted academic practice. No use, distribution or reproduction is permitted which does not comply with these terms. 